\title{
ANALISIS TINDAK TUTUR GURU DAN SISWA DALAM PEMBELAJARAN BAHASA INDONESIA DI SEKOLAH MENENGAH ATAS
}

\author{
Ari Rahma Nur Fitriana, Ani Rakhmawati, Budi Waluyo \\ Universitas Sebelas Maret \\ Email: arirahma440@gmail.com
}

\begin{abstract}
Abstrak: Penelitian ini bertujuan untuk mendeskripsikan dan menganalisis: (1) jenis tindak tutur yang terdapat dalam percakapan guru dan siswa dalam pembelajaran bahasa Indonesia di SMA Negeri 1 Karanganyar tahun ajaran 2017/2018, (2) faktor-faktor yang mempengaruhi tindak tutur guru dan siswa dalam pembelajaran bahasa Indonesia di SMA Negeri 1 Karanganyar tahun ajaran 2017/2018. Penelitian ini merupakan penelitian kualitatif dengan menggunakan pendekatan deskriptif. Penelitian ini dilaksanakan mulai dari bulan Juni 2017 hingga Desember 2018. Sumber data dalam penelitian ini adalah informan yakni guru dan siswa dan peristiwa tutur di dalam pembelajaran bahasa Indonesia. Penelitian ini menggunakan teknik purposive sampling untuk pengambilan sempel. Keabsahan data diuji dengan teknik triangulasi sumber, dan triangulasi teori, sedangkan analisis datayang digunakan dalam penelitian ini adalah model analisis interaktif. Mekanisme analisis interaktif pada dasarnya melibatkan tiga komponen analisis yaitu reduksi data, penyajian data, dan verifikasi data atau menarik kesimpulan. Faktor-faktor yang mempengaruhi tindak tutur guru dan siswa dalam pembelajaran bahasa Indonesia yaitu faktor pebicara, faktor tujuan, faktor situasi, faktor konteks, faktor jalur, faktor media, dan faktor peristiwa.
\end{abstract}

Kata Kunci: a nalisis tindak tutur, faktor-faktor penentu tindak tutur, pembelajaran bahasa Indonesia

\section{TEACHERS AND STUDENTS SPEECH ACT ANALYSIS OF LEARNING INDONESIAN LANGUAGE IN SENIOR HIGH SCHOOL}

\begin{abstract}
The aims of this research are to describe and analyze: (1) the types of speech act between students and teachers dialogue in the Indonesian language learning situation at SMA Negeri 1 Karanganyar, and (2) the influence factors of speech act between students and teachers dialogue in Indonesian language learning at SMA Negeri 1 Karanganyar. This research is belong to a qualitative desciptive research which was conducted from June 2017 to December 2018. The primary data's source in this research is the informan such as students and Indonesian language's teachers, and also the speech act between them at Indonesian language's learning. This research uses purposive sampling technique. Data validity uses a source's and theori's triangulation, while the data analysis using an interactive model that includes data collection, data reduction, data presentation, and conclusion. Based on the results of data analysis, the speech act which often used is illocusion with 37,5 \% of percentage, locusion $73 \%$, and perlocusion $27,5 \%$. The speech act's factors between teachers and students in Indonesian learning are the participants, the aim of speech act, the situation, context, which path, media, and the event of speech act.
\end{abstract}

Keywords: speech act analysis, influence factors of speech act, Indonesian languages learning.

\section{PENDAHULUAN}

Dalam komunikasi sosial, bahasa memiliki peran yang sangat penting sebagai jembatan penghubung yang dapat mengantarkan maksud dan tujuan antara manusia satu dengan manusia yang lain dalam sebuah ujaran. Pentingnya memproduksi ujaran yang baik sesuai situasi kondisi dalam kegiatan berkomunikasi, mendorong manusia untuk 
memahami bahasa secara lebih mendalam. Dalam praktiknya, ilmu pragmatik sering kali digunakan untuk mengkaji studi tentang bahasa lisan yang dapat memperlihatkan seberapa besar penutur dalam melakukan sebuah komunikasi lisan. Hal tersebut sejalan dengan pendapat Amanda dan Leni (2018: 1) tindak tutur berhubungan dengan apa yang dilakukan manusia, termasuk dalam berinteraksi sosial dan komunikasi sosial.

Language is one of the most important parts in social environment. In the study of language, what people do by saying words is called speech acts. Speech act is the study which deals with how to do things with words. Every word belonged to human language represents to the actual world, which means, there must be things, actions, or even characteristics in the actual world that can be seen, or felt when you say the words. It can be defined as communication of human being.

Menurut Chaer dan Agustina dalam Wiranty (2015: 294) mengemukakan tindak tutur merupakan gejala individual, bersifat psikologis, dan keberlangsungannya ditentukan oleh kemampuan bahasa si penutur dalam menghadapi situasi tertentu. Lebih lanjut, Chaer (2004: 49-50) menyatakan bahwa kemampuan penutur dalam berbahasa lisan direalisasikan dalam bentuk komunikasi yang dapat terjadi di dalam situasi tutur. Tindak tutur tidak terlepas dari interaksi yang melibatkan dua pihak, yaitu penutur dan lawan tutur, di dalam waktu, tempat, dan situasi tertentu (Hajijal, Suryadi, dan Bambang, tanpa tahun: 211). Dalam praktik penggunaan di masyarakat, setidaknya ada tiga jenis tindakan yang dapat diwujudkan oleh seorang penutur, yang dinamakan sebagai tindak lokusi, tindak ilokusi, dan tindak perlokusi (Searle dalam Rahardi, 2003: 70). Tindak lokusi merupakan tindak tutur untuk menyatakan sesuatu. Tindak ilokusi adalah tindak tutur yang berfungsi untuk mengatakan atau menginformasikan sesuatu dan dipergunakan untuk melakukan sesuatu.

Tindak perlokusi adalah tindak tutur yang pengutaraannya dimaksudkan untuk memengaruhi lawan tuturnya (Rohmadi, 2004: 30 - 31). Tiga bentuk tindak tutur tersebut dapat muncul antara penutur dan lawan tutur karena pengaruh dari situasi serta konteks dalam sebuah tuturan. Hal ini sesuai dengan pendapat Payuyasa (2014: 3) yang mengungkapkan bahwa analisis terhadap bahasa yang melibatkan konteks dalam penggunaannya, merupakan kajian dari disiplin ilmu pragmatik. Pragmatik hakikatnya menganalisis maksud sebuah tuturan. Percakapan adalah sebuah tuturan yang juga melibakan konteks. Sehingga ada keterkaitan antara bentuk tindak tutur yang diujarkan penutur dengan konteks dan situasi tutur yang berpengaruh terhadap kegiatan berkomunikasi.

Pada saat melakukaan kegiatan berkomunikasi manusia dapat melakukan dengan pengungkapan lisan baik secara langsung maupun tidak langsung. Pengungkapan lisan oleh penutur dapat diutarakan dimana saja. Salah satunya yaitu dalam pembelajaran di kelas. Pengungkapan lisan yang terjadi di dalam kelas sering dilakukan oleh guru dan siswa. Guru harus menciptakan suasana nyaman dan kondusif agar dalam proses menerima pembelajaran dapat berjalan dengan baik. Guru mempengaruhi siswa selama proses pembelajaran berlangsung dengan memberi pengarahan dan stimulus melalui tindak tutur untuk berpartisipasi dalam konteks percakapan(Ardianto, 2013: 1).

Pada Kurikulum 2013, pembelajaran terpusat pada siswa yang artinya siswa dituntut untuk lebih aktif untuk mencari, menemukan,dan mencari materi-materi pembelajaran baik dari buku pegangan siswa, internet, maupun sumber-sumber literasi lain. Menurut Mulyani (Tanpa tahun, 114) dalam implementasi kurikulum 2013, guru dituntut aktif dan kreatif dalam menerapkan pendekatan saintifik. 
Pendekatan saintifik berusaha mendorong guru untuk mengendalikan murid melalui berbagai perintah karena tuntutan dari siklus kegiatan pembelajaran, yakni $5 \mathrm{M}$ (mengamati, menanya, mengumpulkan informasi/mencoba, menalar/mengasosiasi, mengomunikasikan. Kegiatan ini tentu memanfaatkan tindak tutur guru dalam mengelola pembelajaran, baik pada kegiatan awal, inti, dan akhir.

Guru hanya bertugas sebagai fasilitator yang membantu memecahkan setiap pertanyaan-pertanyaan yang diajukan siswa apabila dalam proses pembelajaran menemukan kesulitan. Yuliana (2013: 2) mengemukakan bahwa keberhasilan suatu program pembelajaran ditentukan oleh beberapa komponen dan semua komponen tersebut harus saling berinteraksi. Salah satu komponen tersebut adalah bahasa. Hal ini sejalan dengan pendapat Nababan (1987: 68) bahwa alat terutama dalam interaksi belajar mengajar antara siswa, guru, dan mata pelajaran adalah bahasa.

Dalam proses berinteraksi di kelas, siswa akan mendapatkan segala bentuk informasi. Sumber-sumber informasi didapatkan dari mana saja, termasuk guru. Guru melakukan percakapan tentang materi pembelajaran dan segala hal yang dapat mendukung ketercapaian tujuan pembelajaran yang sudah terencana. Oleh karena itu, guru harus mampu membangun sebuah konteks yang tepat agar terbentuk kesatuan pemahaman antara siswa yang menerima materi dengan guru yang melakukan transfer materi.

Terkait dengan pembelajaran, materi pembelajaran bahasa Indonesia menjadi sangat menarik karena dalam sebuah pembelajaran bahasa terdapat percakapan antara guru dan siswa dimana guru dituntut untuk memiliki banyak kosakata dalam menjelaskan sebuah materi bahasa kepada siswanya. Dalam sebuah tuturan, guru menuturkan tuturan yang spontan dan tidak selalu terpaku pada materi. Guru dapat mengkombinasi kata-kata yang menarik sehingga apa yang disampaikan guru dapat dengan mudah diterima oleh siswanya. Misalnya dalam menerangkan sebuah materi pelajaran, seorang guru dapat memulai pelajaran dengan menawarkan siswanya untuk berani berpendapat menjelaskan terlebih dahulu materi yang akan dipelajari dengan bahasa sendiri, selain itu guru dapat memuji siswanya yang bisa menjawab pertanyaan dengan tepat, kemudian guru juga tidak segansegan memberikan hukuman kepada siswa yang nakal dan malas. Segala bentuk tuturan tuturan tersebut, dapat membentuk serta mempengaruhi suasana dalam proses belajar mengajar. Ketika guru memberikan tuturan berupa hukuman kepada siswa yang nakal dan malas, suasana yang terbangun di dalam kelas seketika itu menjadi hening dan tegang. Sebaliknya ketika guru melakukan tindak tutur ekspresif misalnya mnegucapkan terima kasih kepada siswa yang telah membantu menghapuskan papan tulis yang kotor, memuji siswa yang dapat menjawab soalsoal dengan tepat, atau bahkan mengucapkan selamat kepada siswanya yang mendapatkan rangking di kelas akan terbentuk suasana yang damai dan bahagia.

Begitu pentingnya sebuah tindak tutur yang diucapkan guru dalam sebuah proses pembelajaran di kelas hingga berdampak bahwa guru sebagai penggerak roda suasana pembelajaran seperti menjalin sebuah keakraban maupun menciptakan sebuah ketegangan. Hal tersebut tentu akan berpengaruh terhadap proses belajar mengajar di kelas apakah dapat berjalan sesuai harapan ataukah jauh dari ekspektasi yang diharapkan sebelumnya. Siswa dengan suasana belajar yang baik, akan mudah menerima serta menyerap apapun yang dikatakan guru kepadanya, sebaliknya dengan suasana yang tegang dan muncul perasaan takut dalam hatinya maka penerimaan materi dari guru tidak akan maksimal.

Alasan peneliti memilih topik penelitian ini adalah peneliti ingin mengetahui bentuk-bentuk tindak tutur yang sering digunakan guru maupun siswa 
di kelas pada saat melakukan kegiatan belajar di kelas. Selain itu, peneliti juga ingin mengetahui faktor-faktor apa saja yang mempengaruhi guru dan siswa melakukan tindak tutur tersebut di dalam kelas ketika sedang berlangsung kegiatan belajar mengajar. Hal ini tentu akan menjadi menarik karena peneliti secara langsung melihat, mendengarkan, serta menyimak proses tindak tutur yang terjadi.

Fokus penelitian ini adalah penerapan tindak tutur dalam pembelajaran bahasa Indonesia dengan menganalisis jenis-jenis tindak tutur yang dilakukan guru dan siswa serta faktor-faktor yang mempengaruhi percakapan guru dan siswa dalam pembelajaran bahasa Indonesia. Berdasarkan latar belakang di atas, penulis memfokuskan perhatian pada penggunaan tindak tutur guru dan siswa dalam pembelajaran bahasa Indonesia di SMA Negeri 1 Karanganyar. Judul penelitian ini adalah Kajian Tindak Tutur Guru dan Siswa dalam Pembelajaran Bahasa Indonesia (Studi Kasus SMA Negeri 1 Karanganyar).

\section{METODE PENELITIAN}

Penelitian ini merupakan penelitian deskriptif kualitatif, yaitu penelitian yang berbentuk kualitatif. Lokasi penelitian ini dilakukan di SMA Negeri 1 Karanganyar yang beralamat di jalan SoloTawangmangu, Tegalgede, Kecamatan Karanganyar, Kabupaten Karanganyar, Jawa Tengah.Waktu yang diperlukan untuk mengumpulan data penelitian ini selama 2 bulan yaitu mulai September 2017 sampai dengan Oktober 2017. Sumber data dalam penelitian ini berupa informan dan peristiwa. Informan dalam penelitian ini adalah guru dan siswa. Peristiwanya berupa tindak tutur yang terjadi di dalam kelas, bahasa yang digunakan oleh guru dan siswa, dan konteks situasi yang mempengaruhinya. Teknik yang diterapkan untuk menentukan sampel pada penelitian ini adalah purposive sampling. Teknik purposive sampling merupakan teknik penentuan sampel dengan pertimbangan khusus sehingga layak dijadikan sampel (Noor, 2012: 155).

Pengumpulan data dalam penelitian ini menggunakan teknik obeservasi, wawancara, teknik rekam, teknik simak catat. Menurut Widoyoko (2017: 46) observasi biasa diartikan sebagai pengamatan dan pencatatan secara sistematik terhadap unsur-unsur yang nampak dalam suatu gejala pada objek penelitian. Menurut Widoyoko (2017: 40) wawancara merupakan suatu proses tanya jawab atau dialog secara lisan antara pewawancara (interviewer) dengan responden atau orang yang diintervieu (interviewee) dengan tujuan untuk memperoleh informasi yang dibutuhkan oleh peneliti. Teknik rekam yaitu pemerolehan data dengan cara merekam pemakaian bahasa lisan dalam berkomunikasi. Menurut Sadaryanto dalam Kesuma (2007: 44-45) teknik rekam adalah teknik penjaringan data dengan merekam penggunaan bahasa. Penelitian menggunakan teknik rekam karena data yang diambil adalah data pemakaian bahasa secara lisan, sehingga diperlukan alat perekam untuk menangkap setiap informasi dan membantu dalam menginterpretasikan makna yang terkandung di dalam tuturan. Menurut Mahsun (2005: 242) teknik simak adalah teknik yang digunakan untuk memperoleh data dengan melakukan penyimakan terhadap penggunaan bahasa. Kemudian teknik catat menurut Kesuma (2007: 45) adalah teknik menjaring data dengan mencatat hasil penyimakan data. Teknik Simak Catat ini ada dua. Pertama, peneliti menyimak tindak tutur guru dan siswa dan mencatat hal-hal yang tidak bisa terekam dengan alat perekam. Kedua, teknik simak yang dilakukan dengan menyimak rekaman data yang diperoleh di lapangan, kemudian dilanjutkan dengan kegiatan meenyajikan hasil rekaman dalam bentuk transkip rekaman.

Validasi data dalam penelitian ini menggunakan teknik triangulasi sumber 


\begin{tabular}{|c|c|c|c|}
\hline No & Pelaku & $\begin{array}{c}\text { Contoh } \\
\text { Percakapan }\end{array}$ & Kode \\
\hline 003 & $\begin{array}{l}\text { Pak } \\
\text { Guru }\end{array}$ & $\begin{array}{l}\text { (Duduk } \\
\text { menyilangkan kaki) } \\
\text { Anak-anak apakah } \\
\text { kau tau...20 persen } \\
\text { saja yang menguasai } \\
\text { kekuasaan.. kekayaan } \\
\text { ekonomi yang luar } \\
\text { biasa. } \\
\text { Anda nanti.... kelas } \\
\text { ini...jadi } \\
\text { alumni....hanya } 20 \\
\text { persen yang berhasil } \\
\text { keluar Indonesia. } \\
\text { Saya memikirkan } \\
\text { alumni saya, } \\
\text { angkatan } \\
\text { saya...saya di } \\
\text { kampung.. semua } \\
\text { Nah, walaupun } 20 \\
\text { persen yang hebat } \\
\text { ini yang } \\
\text { tekun...diperlukan } \\
\text { 80 persen sikap, } \\
\text { darah, waktu, } \\
\text { biaya,dan } \\
\text { sebagainya untuk } \\
\text { berhasil...itulah } \\
\text { tekad. Kita berjanji } \\
\text { akan menggunakan } \\
\text { akal sehat kita. }\end{array}$ & $\begin{array}{c}\text { TTLP } \\
\text { BI/IP } \\
\text { A1 } \\
\text { TTLP } \\
\text { BI/IP } \\
\text { A1 } \\
\\
\text { TTPP } \\
\text { BI/IP } \\
\text { A1 }\end{array}$ \\
\hline 004 & $\begin{array}{l}\text { Siswa- } \\
\text { siswi }\end{array}$ & $\begin{array}{l}\text { (Diam dan } \\
\text { mendengarkan apa } \\
\text { yangdikatakan Pak } \\
\text { guru) }\end{array}$ & \\
\hline
\end{tabular}

dan triangulasi metode. Analisis data yang digunakan dalam penelitian ini adalah model analisis interaktif atau interactive model of analysis. Analisis data meliputi pengumpulan data, reduksi data, penyajian data, dan penarikan kesimpulan. Tahapan penelitian dimulai dari tahap persiapan, pelaksanaan, dan penyusunan laporan.

\section{HASIL DAN PEMBAHASAN}

Jenis-Jenis Tindak Tutur Percakapan Guru dengan Siswa dalam Pembelajaran Bahasa Indonesia SMA Negeri 1 Karanganyar

Jenis tindak tutur guru dan siswa dalam pembelajaran bahasa Indonesia di SMA Negeri 1 Karanganyar mencakup tiga jenis tindak tutur, yaitu tindak tutur lokusi, ilokusi, dan perlokusi. Selain menemukan jenis tindak tutur yang ada dalam pembelajaran bahasa Indonesia di SMA Negeri 1 Karanganyar khususnya pada kelas X IPA 1 dan X IPA 2, peneliti juga menganalisis faktor-faktor yang mempengaruhi percakapan guru dengan siswa dalam pembelajaran bahasa Indonesia SMA Negeri 1 Karanganyar.

Berikut ini merupakan tabel frekuensi perwujudan tindak tutur guru dan siswa dalam pembelajaran Bahasa Indonesia di SMA Negeri 1 Karanganyar khususnya pada kelas X IPA 1 dan X IPA 2.

\begin{tabular}{ccccc}
\hline & \multirow{2}{*}{ Jenis } & \multicolumn{2}{c}{ Jumlah } & \\
\cline { 3 - 4 } No & Tindak & \multicolumn{2}{c}{ Data } & Persentase \\
\cline { 3 - 4 } & Tutur & IPA & IPA & \\
& & $\mathbf{1}$ & $\mathbf{2}$ & \\
\hline 1 & Lokusi & 33 & 40 & $35 \%$ \\
\hline 2 & Ilokusi & 37 & 41 & $37,5 \%$ \\
\hline 3 & Perlokusi & 32 & 25 & $27,5 \%$ \\
\hline & Total & 102 & 106 & $100 \%$ \\
\hline
\end{tabular}

Tindak Tutur Lokusi

Tindak tutur lokusi merupakan tindak tutur yang menyatakan suatu informasi. Total dari seluruh data tindak tutur dalam penelitian ini sebanyak 208. 73 data diantaranya merupakan tindak tutur lokusi atau sebesar 35\%. Contoh analisis data mengenai tindak tutur lokusi akan dijabarkan di bawah ini:

Data 003 merupakan tindak tutur lokusi guru yakni guru memberikan pengantar sebelum masuk ke materi pelajaran. Guru hanya menyampaikan sedikit informasi kepada siswa bahwa dimasa yang akan datang hanya 20 persen manusia yang menguasai kekayaan ekonomi. Siswa yang mendengar hal tersebut tidak bereaksi apa-apa karena hal tersebut hanya sekadar informasi pembuka dalam memulai pelajaran dan tidak ada hubungannya dengan materi pelajaran yang akan diajarkan guru.

\section{Tindak Tutur Ilokusi}

Tindak tutur ilokusi menempati urutan pertama dalam pembelajaran bahasa Indonesia. Tindak tutur ilokusi terdapat 78 data atau sebanyak 37,5\%. Dalam pembelajaran bahasa Indonesia guru banyak menawarkan kepada siswa untuk menjawab, beragumen, maupun 
mengungkapkan pendapat. Selain itu, tindak tutur ilokusi yang diutarakan dalam pembelajaran yakni menyuruh, memberi nasihat, meminta, memohon, menolak, memuji, meminta maaf, berterima kasih dan menyimpulkan. Berikut ini merupakan contoh analisis data tindak tutur ilokusi di kelas X IPA 1:

\begin{tabular}{|c|c|c|c|c|}
\hline No & Pelaku & & $\begin{array}{c}\text { Contoh } \\
\text { Percakapan } \\
\end{array}$ & Kode \\
\hline 007 & $\begin{array}{l}\text { Pak } \\
\text { Guru }\end{array}$ & : & $\begin{array}{l}\text { Siapa yang } \\
\text { mau baca? }\end{array}$ & $\begin{array}{c}\text { TTIP } \\
\text { BI/IP } \\
\text { A1 }\end{array}$ \\
\hline 008 & Siswi & : & $\begin{array}{l}\text { (Seorang siswi } \\
\text { berhijab yang } \\
\text { duduk di } \\
\text { depan meja } \\
\text { pak Guru } \\
\text { mengacungkan } \\
\text { jari) Saya Pak. }\end{array}$ & \\
\hline 009 & $\begin{array}{l}\text { Pak } \\
\text { Guru }\end{array}$ & : & Yak & \\
\hline 010 & $\begin{array}{l}\text { Siswa- } \\
\text { siswi }\end{array}$ & : & $\begin{array}{l}\text { (Suasana } \\
\text { menjadi } \\
\text { sedikit gaduh) } \\
\text { Ciee.. }\end{array}$ & \\
\hline 011 & $\begin{array}{l}\text { Pak } \\
\text { Guru }\end{array}$ & : & $\begin{array}{l}\text { (Memberikan } \\
\text { buku kepada } \\
\text { siswa) Pokoke } \\
\text { tidak saya } \\
\text { tunjuk, kalau } \\
\text { ada yang mau } \\
\text { sempat baca, } \\
\text { saya carikan } \\
\text { buku yang.. }\end{array}$ & $\begin{array}{c}\text { TTP } \\
\text { PBI/I } \\
\text { PA1 }\end{array}$ \\
\hline 012 & Siswi & : & $\begin{array}{l}\text { (Seorang siswi } \\
\text { yang akan } \\
\text { membaca } \\
\text { kisah di depan } \\
\text { kelas } \\
\text { memotong } \\
\text { pembicaraan } \\
\text { Pak guru) } \\
\text { Yang mana, } \\
\text { Pak? }\end{array}$ & $\begin{array}{c}\text { TTIP } \\
\text { BI/IP } \\
\text { A1 }\end{array}$ \\
\hline 013 & $\begin{array}{l}\text { Pak } \\
\text { Guru }\end{array}$ & : & $\begin{array}{l}\text { Yang itu tadi } \\
\text { (sambil } \\
\text { menunjuk) }\end{array}$ & $\begin{array}{c}\text { TTLP } \\
\text { BI/IP } \\
\text { A1 }\end{array}$ \\
\hline
\end{tabular}

Konteks data 007 guru menawarkan kepada siswa apakah ada siswa yang mau untuk membacakan cerita di depan kelas. Menawarkan termasuk dalam bentuk tindak tutur ilokusi komisif. Kemudian ada seorang siswi yang maju mendekati meja guru untuk mengambil buku yang akan dibaca, karena masih ragu bacaan mana yang akan dibaca, siswi tersebut bertanya kepada guru bagian mana yang akan dibaca (data 012).

\section{Tindak Tutur Perlokusi}

Tindak tutur perlokusi menempati urutan ketiga dalam pembelajaran bahasa Indonesia di kelas X IPA 1 dan X IPA 2 SMA Negeri 1 Karanganyar. Terdapat 57 data tindak tutur perlokusi atau sebanyak $27,5 \%$. Contoh tindak tutur perlokusi di kelas X IPA 2 yaitu:

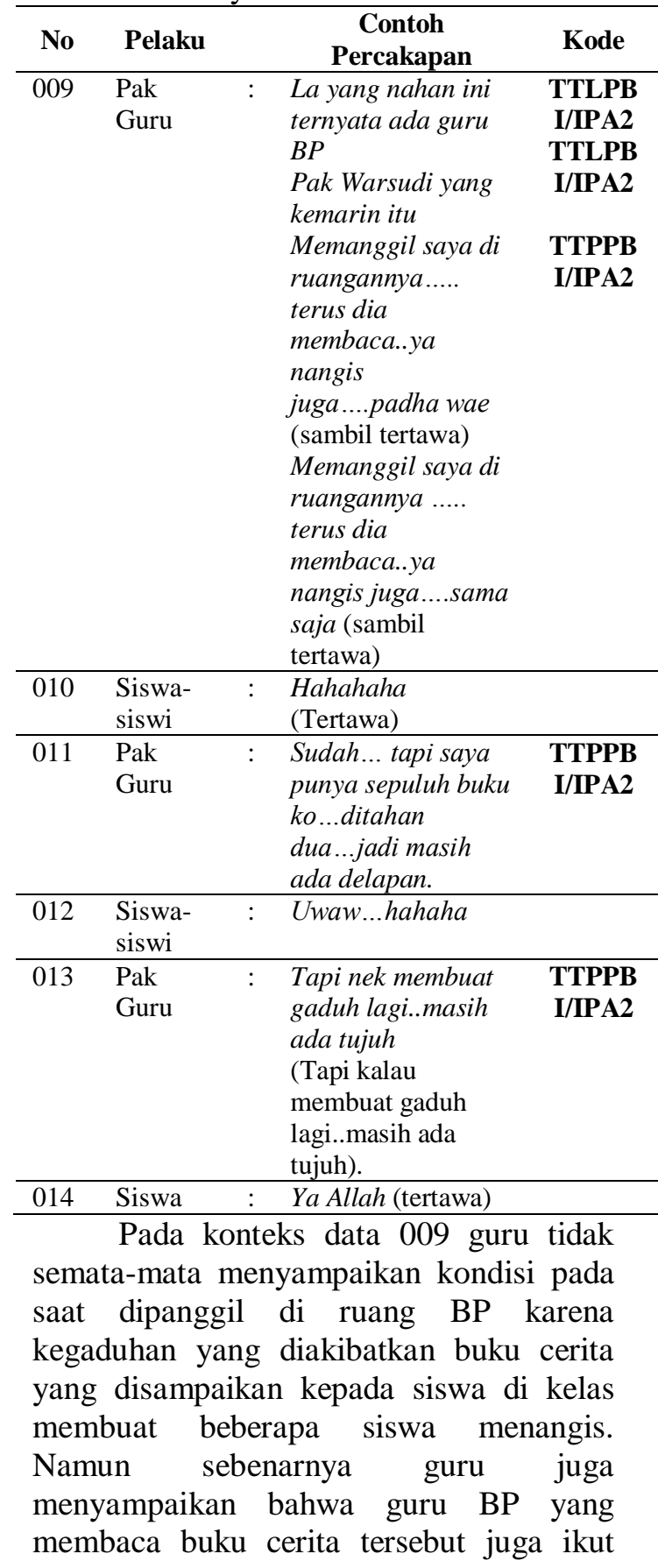


menangis. Artinya sama ketika cerita tersebut dibacakan dapat membuat pendengarnya terharu dan sedih. Data 011 guru menyampaikan kepada siswa bahwa 2 buku cerita beliau ditahan guru BP dan masih ada 8 buku cerita lagi yang ada di rumah. Efek dari tuturan tersebut siswa menjadi takjub dengan banyaknya buku yang masih dimiliki guru walaupun sudah ditahan guru BP sebanyak 2 buah, namun beliau masih mempunyai 8 buku lagi. Siswa menanggapinya dengan tertawa. Dengan demikian, dapat disimpulkan bahwa dalam sebuah pertuturan antara penutur dan lawan tutur dapat mengandung tiga jenis tindak tutur, yakni tindak tutur lokusi, tindak tutur ilokusi, maupun tindak tutur perlokusi.

Faktor-Faktor yang Mempengaruhi Tindak Tutur Percakapan Guru dengan Siswa dalam Pembelajaran Bahasa Indonesia SMA Negeri 1 Karanganyar.

Peneliti menganalisis faktor-faktor yang mempengaruhi tindak tutur percakapan guru dengan siswa dalam pembelajaran Bahasa Indonesia di SMA Negeri 1 Karanganyar.

Peneliti menggunakan teori faktor penentu komunikasi yang ditulis Muhammmad Rohmadi dalam bukunya yang berjudul Pragmatik: Teori dan Analisis tahun 2017. Rohmadi (2017: 7) mengungkapkan bahwa kemampuan menggunakan bahasa dalam komunikasi perlu menyesuaikan bentuk atau ragam bahasa dengan faktor-faktor penentu tindak komunikatif. Faktor-faktor tersebut antara lain: siapa berbahasa dengan siapa, untuk tujuan apa, dalam situasi apa, dalam konteks apa (peserta lain,kebudayaan, dan suasana), jalur yang mana (lisan atau tulisan), media apa (tatap muka, telepon, surat, dan lain-lain), dan dalam peristiwa apa (bercakap-cakap, ceramah, atau upacara).

Pendapat tersebut sejalan dengan pendapat Emike (2013: 2) yang memaparkan faktor penentu tindak tutur sebagai berikut:
Speech act study is essentially immersed in pragmatics. The major concerns of pragmatics include: speech acts (when we speak, we perform various actions with our words); presuppositions (in communicative events, things which participants take for granted are said to be presuppositions about the context); intentions (these are participants' communicative goals); implicatures (implied issues in an utterance); contexts (the relevant aspects of the physical or social setting of an utterance or discourse); inferences (making logical conclusions from available contextual data); non-verbal communication (gestures, dressing and movements).

Berikut ini merupakan penjabaran dari faktor-faktor yang mempengaruhi terjadinya tindak tutur:

\section{Faktor Pebicara}

Faktor pebicara dalam penelitian ini meliputi guru dan siswa. Guru lebih banyak bertindak sebagai pengirim pesan, dan siswa lebih banyak bertindak sebagai penerima pesan. Contoh tuturan yang memperhatikan faktor partisipan terdapat pada data di bawah ini:

\begin{tabular}{|c|c|c|c|c|}
\hline No & Pelaku & & $\begin{array}{c}\text { Contoh } \\
\text { Percakapan }\end{array}$ & Kode \\
\hline 044 & Siswi & : & $\begin{array}{l}\text { Dengan tata } \\
\text { organisasi } \\
\text { tertentu } \\
\text { (saling } \\
\text { bersahutan) } \\
\text { (saling } \\
\text { bersahutan) }\end{array}$ & $\begin{array}{l}\text { TTIP } \\
\text { BI/IP } \\
\text { A2 }\end{array}$ \\
\hline 045 & $\begin{array}{l}\text { Pak } \\
\text { Guru }\end{array}$ & : & $\begin{array}{l}\text { Tata } \\
\text { organisasi } \\
\text {...te...tentu..iy } \\
\text { a...trus }\end{array}$ & $\begin{array}{l}\text { TTLP } \\
\text { BI/IP } \\
\text { A2 }\end{array}$ \\
\hline 046 & Siswa & : & $\begin{array}{l}\text { Makna-makna } \\
\text { secara } \\
\text { mendetail }\end{array}$ & $\begin{array}{l}\text { TTIP } \\
\text { BI/IP } \\
\text { A2 }\end{array}$ \\
\hline
\end{tabular}

\section{Faktor Tujuan Tutur}

Faktor tujuan tutur mengacu pada suatu hal yang ingin didapatkan dalam sebuah proses tindak tutur. Contoh tuturan 
yang memperhatikan faktor tujuan terdapat pada data:

\begin{tabular}{|c|c|c|c|c|}
\hline No & Pelaku & & $\begin{array}{c}\text { Contoh } \\
\text { Percakapan }\end{array}$ & Kode \\
\hline 031 & $\begin{array}{l}\text { Pak } \\
\text { Guru }\end{array}$ & : & $\begin{array}{l}\text { Buka mbah } \\
\text { google! } \\
\text { Anda disuruh } \\
\text { orang tua } \\
\text { membawa HP } \\
\text { itu untuk } \\
\text { menjelajah.. } \\
\text { HP mahal- } \\
\text { mahal kalau } \\
\text { tidak ada } \\
\text { kuotanya dijual } \\
\text { aja untuk } \\
\text { membeli kuota.. }\end{array}$ & $\begin{array}{c}\text { TTIP } \\
\text { BI/IP } \\
\text { A2 }\end{array}$ \\
\hline 032 & $\begin{array}{l}\text { Siswa- } \\
\text { siswi } \\
\end{array}$ & : & $\begin{array}{l}\text { Hahaha } \\
\text { (tertawa) }\end{array}$ & \\
\hline 033 & $\begin{array}{l}\text { Pak } \\
\text { Guru }\end{array}$ & : & Dibaca! & $\begin{array}{c}\text { TTIP } \\
\text { BI/IP } \\
\text { A2 }\end{array}$ \\
\hline 034 & Siswa & : & $\begin{array}{l}\text { (Berbicara } \\
\text { dengan suara } \\
\text { yang lirih) } \\
\text { Naskah yang } \\
\text { berupa kata- } \\
\text { kata. }\end{array}$ & \\
\hline
\end{tabular}

Konteks data diatas terjadi di kelas X IPA 2. Tuturan pada data 031tersebut diujarkan dengan maksud untuk menyuruh siswa menggunakan telepon genggamnya kemudian membuka aplikasi google untuk mencari pengertian tentang naskah. Selain itu guru mengujarkan hal tersebut agar siswa lebih aktif mencari sendiri jawaban dari pertanyaan yang diujarkan guru. Guru bermaksud agar siswa juga lebih peka dan cekatan untuk merespon ujaran yang disampaikan.

\section{Faktor Situasi}

Keadaan atau situasi juga merupakan faktor yang mempengaruhi sebuah tindak tutur. Hal tersebut sesuai dengan pendapat Hymes dalam Chaer dan Leonie (2004: 50) yang menyatakan bahwa scene mengacu pada situasi tutur, tempat dan waktu. Dalam data berikut ini, peneliti menemukan 2 situasi yang berbeda yakni sitiuasi formal dan situasi nonformal. Contoh tuturan seperti data berikut:

Situasi Formal

\begin{tabular}{clccc}
\hline No & Pelaku & & $\begin{array}{c}\text { Contoh } \\
\text { Percakapan }\end{array}$ & Kode \\
\hline 003 & Pak & $:$ & (Duduk & TTLP \\
\hline
\end{tabular}

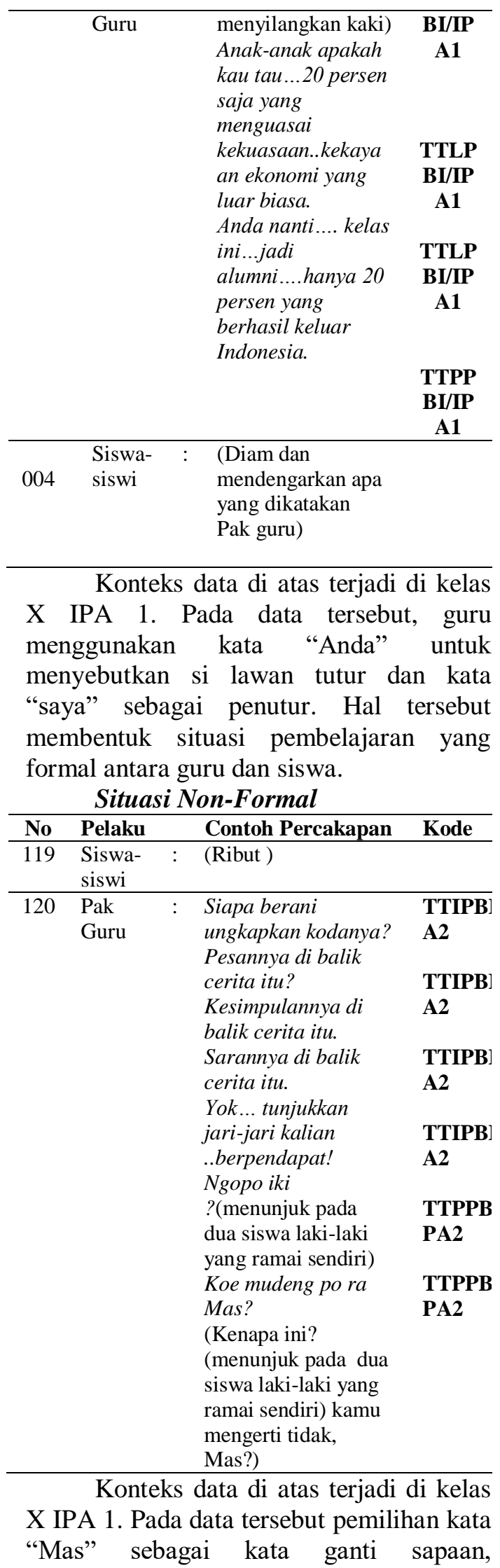


kemudian dilanjutkan dengan penggunaan bahasa Jawa ngoko, dan penggunan bahasa Indonesia tidak baku menciptakan suasana tidak formal, cair, dan akrab.

\section{Faktor Konteks}

Menurut Sari (2014: 74) context mengacu pada situasi nonlinguistik yang ada saat tuturan terjadi. Sedangkan Rahardi (2000: 480) memberi batasan bahwa konteks sebagai latar belakang pengetahuan yang dimiliki bersama oleh penutur dan petutur serta yang menyertai sebuah pertuturan. Contohnya seperti data berikut:

\begin{tabular}{|c|c|c|c|c|}
\hline No & Pelaku & & $\begin{array}{c}\text { Contoh } \\
\text { Percakapan }\end{array}$ & Kode \\
\hline 051 & $\begin{array}{l}\text { Pak } \\
\text { Guru }\end{array}$ & : & $\begin{array}{l}\text { Abstraksi.... } \\
\text { siapa sudah } \\
\text { menemukan } \\
\text { pengertiannya } \\
? \\
\text { Dibaca yok! } \\
\text { Gambaran isi. } \\
\text { Ada kok di } \\
\text { bab } 2 \text { di } \\
\text { bukumu... } \\
\text { coba cari } \\
\text { dulu! } \\
\text { Jadi, sebuah } \\
\text { cerita } \\
\text { anekdot pasti } \\
\text { didahului } \\
\text { gambaran isi } \\
\text { secara } \\
\text { singkat...seca } \\
\text { ra umum. } \\
\text { Orientasi } \\
\text { artine opo? } \\
\text { (Orientasi } \\
\text { artinya apa?) }\end{array}$ & $\begin{array}{l}\text { TTIPBI } \\
\text { /IPA2 } \\
\text { TTIPBI } \\
\text { /IPA2 } \\
\text { TTPPB } \\
\text { I/IPA2 } \\
\text { TTIPBI } \\
\text { /IPA2 } \\
\text { TTIPBI } \\
\text { /IPA2 }\end{array}$ \\
\hline 052 & Siswa & : & $\begin{array}{l}\text { Awal } \\
\text { kejadian... }\end{array}$ & $\begin{array}{l}\text { TTIPBI } \\
\text { /IPA2 } \\
\end{array}$ \\
\hline 053 & $\begin{array}{l}\text { Pak } \\
\text { Guru }\end{array}$ & : & $\begin{array}{l}\text { Cerita } \\
\text { awal.... yang } \\
\text { menggambark } \\
\text { an pelaku, } \\
\text { tempatnya, } \\
\text { latarnya. } \\
\text { Kalau krisis } \\
\text { apa artinya? }\end{array}$ & $\begin{array}{l}\text { TTIPBI } \\
\text { /IPA2 }\end{array}$ \\
\hline
\end{tabular}

Konteks pada data di atas terjadi ketika guru bertanya kepada siswa tentang pengertian dari masing-masing struktur Teks Anekdot.Setelah guru bertanya, siswa hanya diam dan kurang merespon pertanyaan guru. Kemudian guru mengarahkan dan memberitahu bahwa materi tentang teks anekdot tertulis di buku paket Bahasa Indonesia pada bab kedua dengan tuturan "Ada kok di bab 2 dibukumu...." Siswa yang mendengar hal itu langsung mengerti maksud guru mengatakan hal tersebut yakni menyuruh siswa untuk membuka materi di bab 2 .

\section{Faktor Jalur}

Faktor jalur bahasa juga mempengaruhi tindak tutur guru dan siswa. Faktor ini mengacu pada jalur bahasa yang digunakan bisa dengan lisan maupun tulis. Pada penelitian ini, peneliti tidak hanya menemukan jalur bahasa lisan yang digunakan guru dalam mengajar, namun peneliti juga menemukan bahwa jalur tulisan juga digunakan dalam pembelajaran. Jalur tulis dalam data di bawah ini, guru membuat mind mapping untuk mengilustrasikan strutur anekdot. Contoh tuturan yang memperhatikan faktor jalur terdapat pada data berikut:

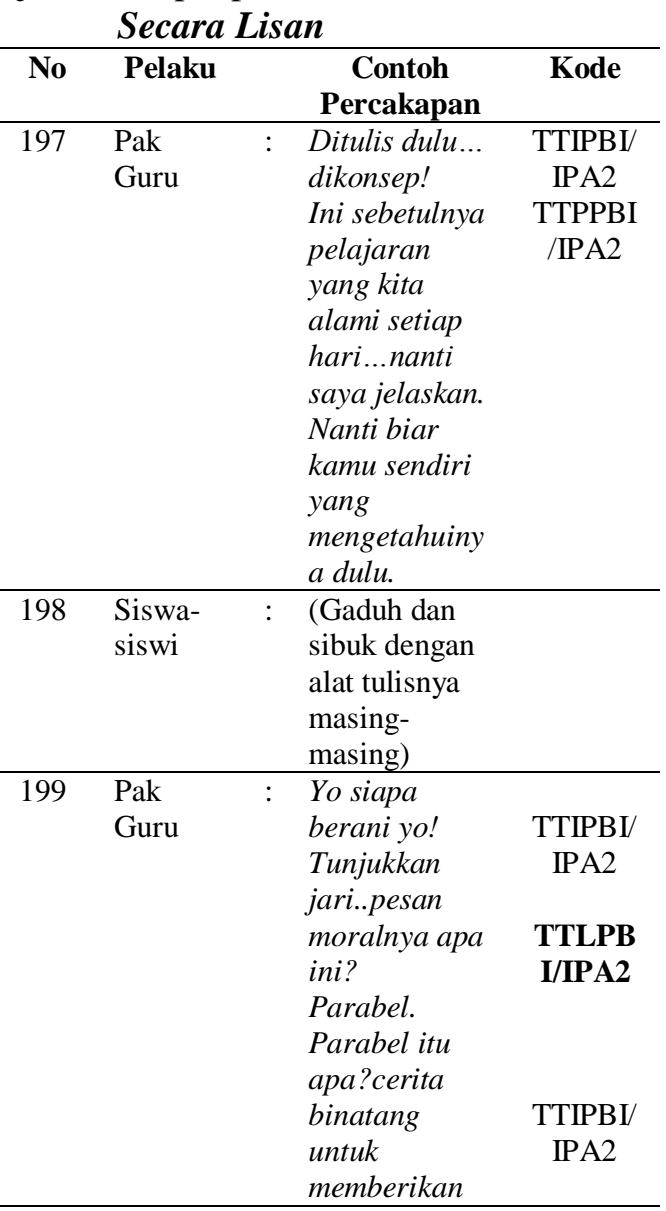




\begin{tabular}{|c|c|}
\hline $\begin{array}{l}\text { kritikan, } \\
\text { inspirasi, bagi } \\
\text { pembacanya } \\
\text {....kita semua } \\
\text { ini (sambil } \\
\text { menujukkan } \\
\text { jari ke dada) } \\
\text { Jadi, binatang } \\
\text { saja sulit } \\
\text { diajar...apala } \\
\text { gi kita... dan } \\
\text { kita itu lebih } \\
\text { dari } \\
\text { binatang.... } \\
\text { Dan kita } \\
\text { mempunyai } \\
\text { aneka } \\
\text { macam... } \\
\text { Enek sing } \\
\text { pinter lari, } \\
\text { ning raiso } \\
\text { pinter manjat } \\
\text { (Ada yang } \\
\text { pandai berlari, } \\
\text { tetapi tidak } \\
\text { pandai } \\
\text { memanjat) } \\
\text { Enek sing } \\
\text { pinter } \\
\text { renang....blas } \\
\text { ora iso lari } \\
\text { (Ada yang } \\
\text { pandai } \\
\text { berenang...sa } \\
\text { ma sekali } \\
\text { tidak bias } \\
\text { berlari) } \\
\text { Enek sing } \\
\text { pinter...meng } \\
\text { gali lubang, } \\
\text { ning blas ora } \\
\text { iso } \\
\text { terbang...enek } \\
\text {. } \\
\text { (Ada yang } \\
\text { bisa menggali } \\
\text { lubang, tetapi } \\
\text { sama sekali } \\
\text { tidak bisa } \\
\text { terbang)...ada } \\
\text {. } \\
\text { Laa kui.... } \\
\text { menggambark } \\
\text { an apa dibalik } \\
\text { cerita ini? } \\
\text { (Laa itu.... } \\
\text { menggambark } \\
\text { an apa dibalik } \\
\text { cerita ini?) } \\
\text { Seharusnya } \\
\text { sekolah yang } \\
\text { ideal... yang }\end{array}$ & $\begin{array}{l}\text { TTIPBI/ } \\
\text { IPA2 } \\
\text { TTIPBI/ } \\
\text { IPA2 }\end{array}$ \\
\hline
\end{tabular}

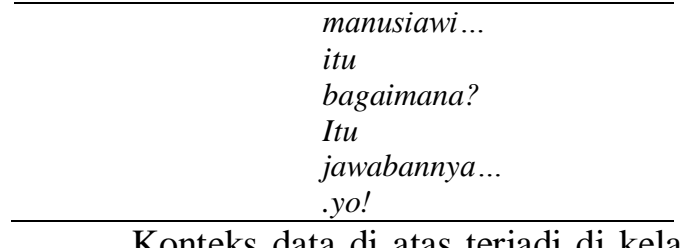

Konteks data di atas terjadi di kelas $X$ IPA 2. Tuturan ini berlangsung di tengah-tengah jam pelajaran ketika guru selesai memperdengarkan contoh teks anekdot. Guru meminta siswa dengan menuliskan pesan moral yang dapat diambil dari cerita anekdot tersebut. Pada tuturan tersebut menggunakan jalur lisan. Guru menyampaikan perintah secara langsung di hadapan para siswa. Siswa yang mendengar hal tersebut kemudian langsung mempersiapkan alat tulis dan segera menuliskan pesan moral dari cerita anekdot tersebut.

Secara Tulisan

\begin{tabular}{|c|c|c|c|c|}
\hline No & Pelaku & & $\begin{array}{l}\text { Contoh } \\
\text { Percakapan }\end{array}$ & Kode \\
\hline 048 & Siswa & : & Genre & \\
\hline 049 & $\begin{array}{l}\text { Pak } \\
\text { Guru }\end{array}$ & : & $\begin{array}{l}\text { Atau genre } \\
\text { jenis teks } \\
\text { tertentu..kare } \\
\text { na genrenya } \\
\text {.jenisnya itu } \\
\text { adalah } \\
\text { anekdot..mak } \\
\text { a strukturnya } \\
\text { meliputi... } \\
\text { yang pertama } \\
\text { (sambil } \\
\text { menulis di } \\
\text { papan tulis) } \\
\text { abstraksi..yan } \\
\text { g kedua } \\
\text { orientasi...ya } \\
\text { ng ketiga } \\
\text { krisis...dan } \\
\text { yang keempat } \\
\text { adalah } \\
\text { reaksi..itu....y } \\
\text { ang terakhir } \\
\text { koda...nah } \\
\text { seperti itu. } \\
\text { Nah sekarang } \\
\text { kita jelaskan } \\
\text { ini semua } \\
\text { (sambil } \\
\text { menunjuk ke } \\
\text { papan tulis) } \\
\text { Apakah } \\
\text { abstraksi itu? } \\
\text { Ini } \\
\text { dituliss...beda }\end{array}$ & $\begin{array}{l}\text { TTLP } \\
\text { BI/IP } \\
\text { A2 } \\
\\
\text { TTIP } \\
\text { BI/IP } \\
\text { A2 }\end{array}$ \\
\hline
\end{tabular}




\begin{tabular}{|c|c|c|}
\hline \multicolumn{3}{|c|}{$\begin{array}{l}\text { ne opo? } \\
\text { (Apakah } \\
\text { abstraksi itu? } \\
\text { Ini } \\
\text { dituliss...bed } \\
\text { anya apa?) } \\
\text { (Kemudian } \\
\text { berjalan } \\
\text { menuju meja } \\
\text { guru dan } \\
\text { duduk } \\
\text { kembali) }\end{array}$} \\
\hline \multicolumn{3}{|c|}{$\begin{array}{l}\text { Konteks tuturan di atas terjadi di } \\
\text { kelas X IPA 2. Tuturan guru pada nomor } \\
049 \text { terjadi pada saat guru sedang } \\
\text { menerangkan tentang struktur teks } \\
\text { anekdot. Dari tuturan tersebut guru } \\
\text { mencoba mengilustrasikan struktur teks } \\
\text { anekdot dalam bentuk main mapping di } \\
\text { papan tulis. }\end{array}$} \\
\hline \multicolumn{3}{|c|}{$\begin{array}{l}\text { Struktur teks anekdot di gamba } \\
\text { sedemikian rupa untuk menggiring } \\
\text { pemahaman siswa tentang struktur teks } \\
\text { anekdot. Keempat struktur anekdot yang } \\
\text { meliputi abstraksi, orientasi, krisis dan } \\
\text { reaksi dituliskan secara jelas di papan tulis } \\
\text { Jalur tulis yang dikreasikan guru menjad } \\
\text { sebuah bentuk mind mapping inilah yang } \\
\text { berusaha diilustrasikan sebagai usaha } \\
\text { untuk memudahkan siswa menerima serta } \\
\text { memahami materi struktur teks anekdot. } \\
\text { Faktor Media }\end{array}$} \\
\hline \multicolumn{3}{|c|}{$\begin{array}{l}\text { Faktor penentu tindak tut } \\
\text { selanjutnya yakni media. Faktor } \\
\text { mengacu pada alat atau sarana ya } \\
\text { digunakan untuk menyampaikan informa } \\
\text { Dalam penelitian ini ada dua sarana ya } \\
\text { digunakan guru dalam pembelajaran yak } \\
\text { telepon genggam dan buku bacaan. Cont } \\
\text { tuturan yang memperhatikan faktor med } \\
\text { terdapat pada data berikut: } \\
\text { Telepon Genggam }\end{array}$} \\
\hline $\begin{array}{ll}\text { No } & \text { Pelaku }\end{array}$ & $\begin{array}{c}\text { Contoh } \\
\text { Percakapan }\end{array}$ & Kode \\
\hline $\begin{array}{l}\text { Pak } \\
\text { Guru }\end{array}$ & $\begin{array}{l}\text { Yo.. diterima } \\
\text { kirimane! } \\
\text { (Yo..diterima } \\
\text { kirimannya!) }\end{array}$ & $\begin{array}{c}\text { TTIP } \\
\text { BI/IP } \\
\text { A2 }\end{array}$ \\
\hline 259 Siswa & $\begin{array}{l}\text { (Mengecek } \\
\text { telepon } \\
\text { gengggam } \\
\text { masing-masing) }\end{array}$ & \\
\hline
\end{tabular}

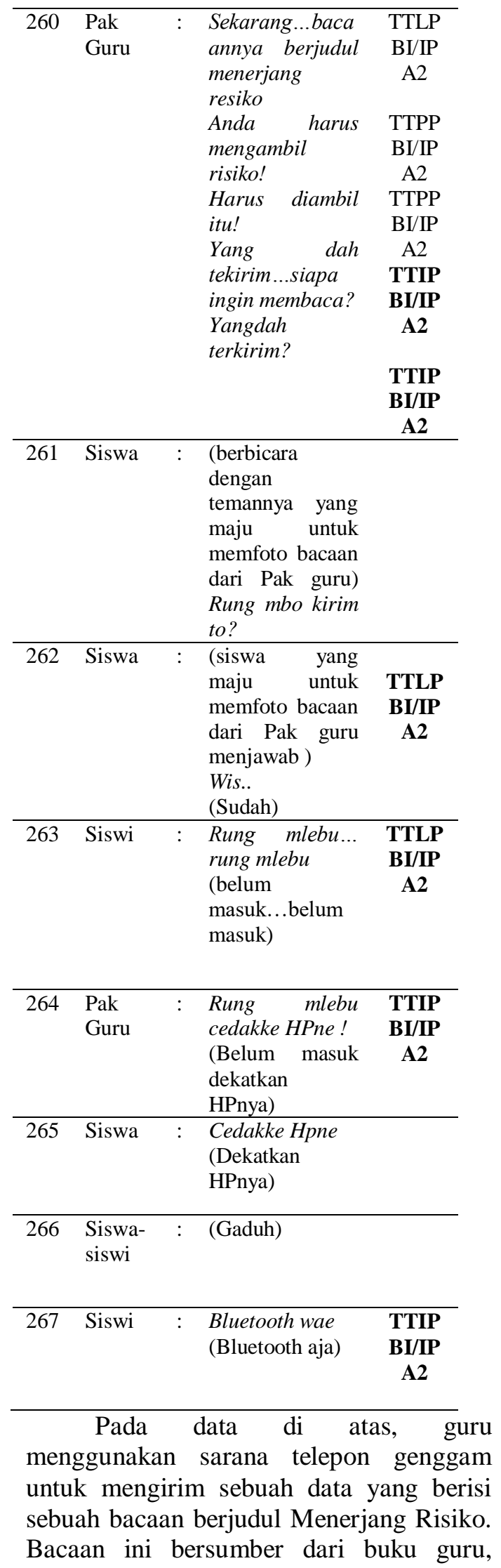


sehingga agar semua siswa dapat membacanya secara lebih jelas maka guru memberikan bacaan tersebut lewat telepon genggam.

Hal ini tentunya sangat mempermudah guru dalam memberikan materi yakni berupa contoh teks. Contoh yang diambil dari sumber yang beraneka ragam dapat menambah keanekaragaman bacaan serta menumbuhkan daya imajinasi siswa dengan lebih kreatif. Sarana yang dipilih yakni telepon genggam dirasa cocok untuk mentrasfer data atau sebuah informasi baru mengingat semua siswa di kelas tersebut sudah mempunyai telepon genggam pribadi sebagai jembatan penghubung komunikasi dalam bentuk teks ini merupakan salah satu alternatif baru yang dapat diterapkan dalam pengajaran bahasa.

Buku Bacaan

\begin{tabular}{|c|c|c|c|c|}
\hline No & Pelaku & & $\begin{array}{c}\text { Contoh } \\
\text { Percakapan }\end{array}$ & Kode \\
\hline 007 & $\begin{array}{l}\text { Pak } \\
\text { Guru }\end{array}$ & & $\begin{array}{l}\text { Siapa yang mau } \\
\text { baca? }\end{array}$ & $\begin{array}{c}\text { TTIP } \\
\text { BI/IP } \\
\text { A1 }\end{array}$ \\
\hline 008 & Siswi & & $\begin{array}{l}\text { (Seorang siswi } \\
\text { berhijab yang } \\
\text { duduk di depan } \\
\text { meja pak Guru } \\
\text { mengacungkan } \\
\text { jari) Saya Pak. }\end{array}$ & \\
\hline 009 & $\begin{array}{l}\text { Pak } \\
\text { Guru }\end{array}$ & & Yak & \\
\hline 010 & $\begin{array}{l}\text { Siswa- } \\
\text { siswi }\end{array}$ & & $\begin{array}{l}\text { (Suasana } \\
\text { menjadi sedikit } \\
\text { gaduh) Ciee.. }\end{array}$ & \\
\hline 011 & $\begin{array}{l}\text { Pak } \\
\text { Guru }\end{array}$ & : & $\begin{array}{l}\text { (Memberikan } \\
\text { buku kepada } \\
\text { siswa) Pokoke } \\
\text { tidak saya } \\
\text { tunjuk, kalau } \\
\text { ada yang mau } \\
\text { sempat baca, } \\
\text { saya carikan } \\
\text { buku yang... }\end{array}$ & $\begin{array}{c}\text { TTPP } \\
\text { BI/IP } \\
\text { A1 }\end{array}$ \\
\hline 012 & Siswi & & $\begin{array}{l}\text { (Seorang siswi } \\
\text { yang akan } \\
\text { membaca kisah } \\
\text { di depan kelas } \\
\text { memotong } \\
\text { pembicaraan } \\
\text { Pak guru) Yang } \\
\text { mana, Pak? }\end{array}$ & $\begin{array}{c}\text { TTIP } \\
\text { BI/IP } \\
\text { A1 }\end{array}$ \\
\hline 013 & $\begin{array}{l}\text { Pak } \\
\text { Guru }\end{array}$ & & $\begin{array}{l}\text { Yang itu tadi } \\
\text { (sambil } \\
\text { menunjuk) }\end{array}$ & $\begin{array}{c}\text { TTLP } \\
\text { BI/IP } \\
\text { A1 }\end{array}$ \\
\hline
\end{tabular}

Pada konteks data di atas terjadi di kelas X IPA 1. Pada tuturan tersebut guru meminta siswa untuk membacakan contoh teks anekdot yang berjudul Tiga Pintu Kebijaksanaan. Contoh teks anekdot ini diambil dari buku milik guru yang sudah dipersiapkan sebelum beliau mengajar. Guru mencoba menerapkan penggunakan media buku bacaan sebagai gambaran untuk siswa bahwa salah satu contoh bentuk teks anekdot yang benar seperti apa yang akan dibacakan. Media bacaan ini diharapkan mampu menjembatani pemahaman siswa tentang contoh dan struktuk teks anekdot yang urut dan lengkap.

\section{Faktor Peristiwa}

Peristiwa atau kejadian yang sedang berlangsung pada saat tuturan disampaikan. Peristiwa yang diteliti adalah tuturan pada awal pembelajaran, selama proses pembelajaran dan akhir pembelajaran. Contohnya seperti data berikut:

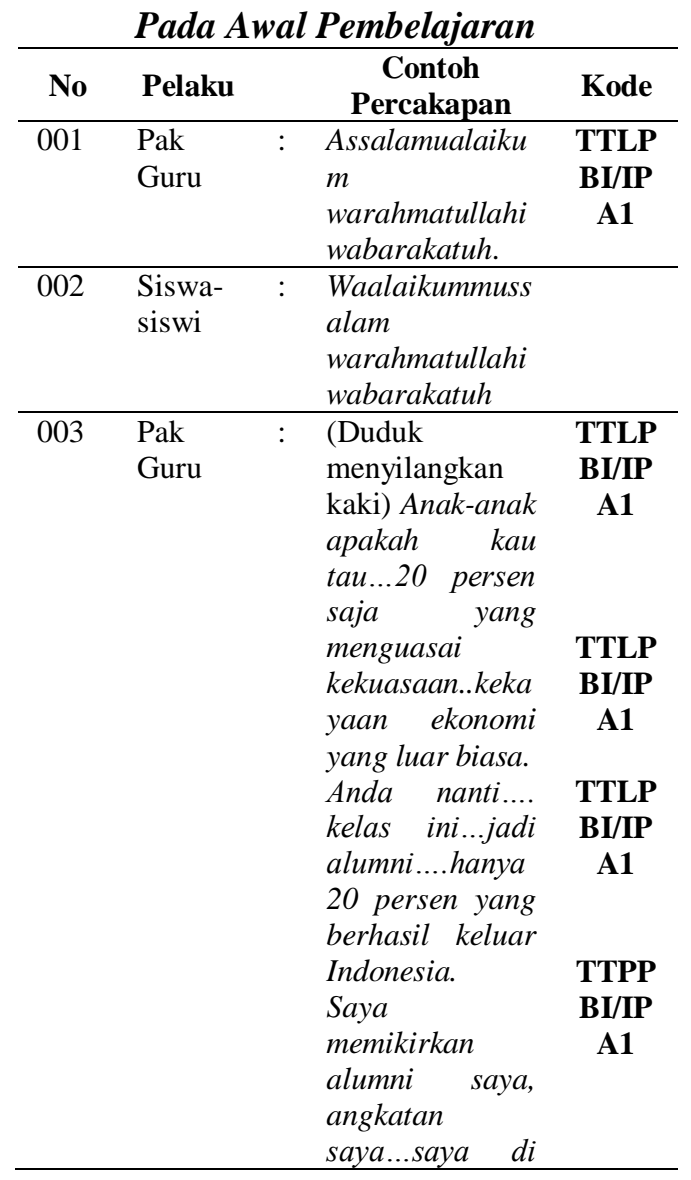




\begin{tabular}{cl}
\hline & kampung..semu \\
& a \\
& Nah, walaupun \\
& 20 persen yang \\
& hebat ini yang \\
& tekun...diperluk \\
& an 80 persen \\
& sikap, darah, \\
& waktu, \\
& biaya,dan \\
& sebagainya \\
& untuk berhasil. \\
& .itulah tekad. \\
& Kita berjanji \\
& akan \\
& menggunakan \\
& akal sehat kita. \\
& (Diam dan \\
& mendengarkan \\
& apa \\
& yangdikatakan \\
& Pak guru) \\
\hline Siswa- & siswi
\end{tabular}

Konteks tuturan di atas terjadi di kelas X IPA 1. Dalam tuturan tersebut guru mengawali pembelajaran dengan mengucapkan salam. Siswa kemudian menjawab salam tersebut. Setelah itu, guru memberikan pembukaan yang berupa motivasi. Tuturan yang mengandung motivasi tersebut disampaikan di awal pembelajaran agar siswa yang mendengar hal tersebut diharapkan mampu membangkitkan semangat, tekad, serta akal sehatnya untuk kemudian dapat melaju meneruskan pembelajaran dengan nyaman dan gembira. Siswa mendengarkan guru dengan antusias terlihat dari sikapnya yang menunjukkan sikap diam namun fokus ke arah guru.

Pada Akhir Pembelajaran

\begin{tabular}{|c|c|c|c|c|}
\hline No & Pelaku & & $\begin{array}{c}\text { Contoh } \\
\text { Percakapan }\end{array}$ & Kode \\
\hline 280 & $\begin{array}{l}\text { Pak } \\
\text { Guru }\end{array}$ & : & $\begin{array}{l}\text { Di balik cerita } \\
\text { ini ada filosofi } \\
\text { hidup...kuncin } \\
\text { ya jelas! } \\
\text { Menerjang } \\
\text { risiko. } \\
\text { Kata kuncinya } \\
\text { begini (sambil } \\
\text { berdiri) } \\
\text { Rencanakan } \\
\text { kehidupanmu, } \\
\text { kalau anda } \\
\text { tidak } \\
\text { merencakan } \\
\text { kehidupanmu }\end{array}$ & $\begin{array}{c}\text { TTIP } \\
\text { BI/IP } \\
\text { A2 }\end{array}$ \\
\hline
\end{tabular}

\begin{tabular}{|c|c|c|c|c|}
\hline & & & $\begin{array}{l}\text {... kehidupan } \\
\text { akan } \\
\text { merencanaka } \\
\text { nти. }\end{array}$ & \\
\hline 281 & $\begin{array}{l}\text { Siswa- } \\
\text { siswi }\end{array}$ & : & $\begin{array}{l}\text { Uweeeeee..(be } \\
\text { rsorak } \\
\text { kemudian } \\
\text { bertepuk } \\
\text { tangan) }\end{array}$ & \\
\hline 282 & $\begin{array}{l}\text { Pak } \\
\text { Guru }\end{array}$ & : & $\begin{array}{l}\text { Anda harus } \\
\text { memilih } . . \\
\text { kalau anda } \\
\text { tidak mau } \\
\text { memilih..anda } \\
\text { akan } \\
\text { dipilihkan...te } \\
\text { rus terjadi. }\end{array}$ & $\begin{array}{c}\text { TTIP } \\
\text { BI/IP } \\
\text { A2 }\end{array}$ \\
\hline 283 & $\begin{array}{l}\begin{array}{l}\text { Siswa- } \\
\text { siswi }\end{array} \\
\end{array}$ & : & $\begin{array}{l}\text { (Bertepuk } \\
\text { tangan) }\end{array}$ & \\
\hline 284 & $\begin{array}{l}\text { Pak } \\
\text { Guru }\end{array}$ & : & $\begin{array}{l}\text { Anda harus } \\
\text { siap..kalau } \\
\text { anda } \\
\text { terlambat...an } \\
\text { da akan } \\
\text { celaka... } \\
\text { Lo piye } \\
\text { ndang? } \\
\text { (Gimana } \\
\text { coba?) }\end{array}$ & $\begin{array}{c}\text { TTIP } \\
\text { BI/IP } \\
\text { A2 }\end{array}$ \\
\hline 285 & $\begin{array}{l}\text { Siswa- } \\
\text { siswi }\end{array}$ & : & $\begin{array}{l}\text { (Bertepuk } \\
\text { tangan) }\end{array}$ & \\
\hline 286 & $\begin{array}{l}\text { Pak } \\
\text { Guru }\end{array}$ & : & $\begin{array}{l}\text { Terus saja } \\
\text { (Berdiri } \\
\text { kemudian } \\
\text { merapikan } \\
\text { tas)Sudah } \\
\text { anak- } \\
\text { anak...kurang } \\
\text { lebihnya } \\
\text { mohon maaf } \\
\text { Wassalammua } \\
\text { laykum } \\
\text { warahmatulla } \\
\text { hi } \\
\text { wabarakatuh }\end{array}$ & $\begin{array}{c}\text { TTIP } \\
\text { BI/IP } \\
\text { A2 } \\
\text { TTLP } \\
\text { BI/IP } \\
\text { A2 }\end{array}$ \\
\hline 287 & $\begin{array}{l}\text { Siswa- } \\
\text { siswi }\end{array}$ & : & $\begin{array}{l}\text { Waalaykumm } \\
\text { ussalam } \\
\text { warahmatulla } \\
\text { hi } \\
\text { wabarakatuh } \\
\text { (sambil } \\
\text { berdiri dan } \\
\text { bertepuk } \\
\text { tangan) }\end{array}$ & \\
\hline 288 & Siswa & : & $\begin{array}{l}\text { Hebat Pak } \\
\text { hebat }\end{array}$ & $\begin{array}{c}\text { TTIP } \\
\text { BI/IP } \\
\text { A2 }\end{array}$ \\
\hline 289 & $\begin{array}{l}\text { Siswa- } \\
\text { siswi }\end{array}$ & : & $\begin{array}{l}\text { Terima kasih } \\
\text { Pak Samsi }\end{array}$ & $\begin{array}{c}\text { TTIP } \\
\text { BI/IP } \\
\text { A2 }\end{array}$ \\
\hline
\end{tabular}


Konteks tuturan diatas terjadi di kelas X IPA 2.Tuturan diatas terjadi di akhir pembelajaran. Guru memberikan kesimpulan dari materi yang disampaikan kemudian melengkapi dengan saran sebagai bahan perenungan siswa. Lalu guru menutup pelajaran dengan menguccapkan salam dalam bahasa Arab. Pemilihan pengucapan salam dalam bahasa Arab dilatarbelakangi oleh agama yang dianut keseluruhan siswa yakni agama Islam. Dengan demikian faktor-faktor tindak tutur di atas sudah sesuai dengan teori yang disampaikan Rohmadi (2017).

\section{SIMPULAN}

Berdasarkan dari penelitian dan pembahasan yang telah diuraikan pada bab sebelumnya dapat ditarik kesimpulan sebagai berikut: jenis tindak tutur yang terdapat dalam pembelajaran bahasa Indonesia di SMA Negeri 1 Karanganyar khususnya kelas X IPA 1 dan X IPA 2 yaitu: tindak tutur lokusi, tindak tutur ilokusi, dan tindak tutur perlokusi. Tindak tutur ilokusi yang muncul dalam pembelajaran bahasa Indonesia di kelas terdiri dari (a) Direktif yang terdiri dari tindak tutur memerintah, memberi nasihat, menyilakan, mengajak, memohon, dan meminta. (b) Asertif, yang terdiri dari memberitahukan, mengemukakan pendapat, mengeluh, menyarankan, dan menyimpulkan. (c) Ekspresif, yang terdiri dari memuji, berterima kasih , meminta maaf. (d) Komisif, terdiri dari menawarkan, mengancam, menolak. Tindak tutur yang dominan digunakan adalah tindak tutur ilokusi yang bersifat direktif. Tuturan ini banyak dituturkan oleh guru kepada siswa dalam pemaparan

\section{REFERENSI}

Amanda, V. \& Leni, M. (2018). Directive Speech Acts Used In Frozen Movie Transcript. JELL. Vol 7. No 1 March 2018.

Ardianto. (2013). Tindak Tutur Direktif Guru dalam Wacana Interaksi materi baik berupa instruksi langsung memerintah, memberi nasihat, menyilakan, mengajak, memohon, dan meminta.

Faktor-faktor yang mempengaruhi percakapan guru dan siswa dalam pembelajaran bahasa Indonesia di SMA Negeri 1 Karanganyar khususnya kelas X IPA 1 dan X IPA 2 yaitu: faktor pebicara, faktor tujuan, faktor situasi, faktor konteks (pesera lain, kebudayaan, dan suasana), faktor jalur (lisan atau tulisan), faktor media (tatap muka, telepon, surat, dan lainlain), dan faktor peristiwa (bercakapcakap, ceramah, atau upacara). Faktor pebicara adalah faktor yang paling dominan mempengaruhi terjadinya peristiwa tutur. Guru sebagai penutur, banyak memberikan umpan tuturan untuk membangkitkan partisipasi siswa. Tuturanturan yang dituturkan guru, baik berbentuk lisan dan tulis mendorong siswa untuk aktif bertanya, memberikan pendapat, dan menampilkan potensi diri siswa. Faktorfaktor lain juga berpengaruh terhadap peristiwa tutur disebut dengan faktor pendukung. Faktor-faktor pendukung tersebut yaitu faktor untuk tujuan apa, faktor dalam situasi apa, faktor dalam konteks apa, faktor jalur yang mana, faktor media apa, dan faktor dalam peristiwa apa.

Peneliti menyarankan kepada peneliti lain yang akan melanjutkan penelitian tentang tindak tutur, untuk mengambil sampel lebih beragam. Lebih lanjut, untuk guru diharapkan lebih banyak berkomunikasi menggunakan bahasa Indonesia yang lebih komunikatif karena selama proses penelitian, guru sebagai penutur lebih sering menggunakan bahasa Jawa Ngoko sebagai bahasa pengantar dalam pembelajaran.

Kelas Anak Tuna Rungu.LITERA. Volume 12. Nomor 1. April 2013.

Chaer, Abdul. (2004). Sosiolinguistik 'Perkenalan Awal'. Jakarta: Rineka Cipta. 
Chaer, A. \& Leonie A. (2004). Sosiolinguistik: Perkenalan awal. Jakarta: Rineka Cipta.

Emike, J.A. (2013). The Illocutionary Frames Principle (IFP) and the Austinian Postulations: A ClauseStructure Investigative Discourse. Global Journal of Human Social Science. Vol. 13. Issue 13. Version 1.0. Year 2013.

Hajijal, S., Suryadi, \& Bambang, J. (Tanpa tahun). Tindak Tutur Ilokusi Guru Bahasa Indonesia pada Proses Pembelajaran di Kelas XI IPA 1 SMAN 9 Kota Bengkulu. Artikel Jurnal Skripsi.

Kesuma, T.M.J. (2007). Pengantar (Metode) Penelitian Bahasa.Yogyakarta.Carasvatibook s.

Mahsun. (2005). Metode Penelitian Bahasa: Tahap Strategi, Metode, dan Tekniknya. Jakarta: PT RajaGrafindo Persada.

Mulyani. (Tanpa tahun). Kajian Pragmatik terhadap Tindak Tutur Direktif Guru SMA dalam Kegiatan Belajar di Kelas. Makalah Seminar Nasional PRASASTI II "Kajian Pragmatik dalam Berbagai Bidang”.

Nababan, P.W.J. (1987). Ilmu Pragmatik: Teori dan Penerapannya. Jakarta: Departemen Pendidikan dan Kebudayaan.

Noor, J. (2012). Metodologi Penelitian: Skipsi, Tesis, Disertasi, dan Karya Ilmiah. Jakarta: Kencana.

Payuyasa, I.N, Sutama, I.M, \& Putrayasa, I.B. (2014). Pelaksanaan Prinsip Kerja Sama pada Tindak Tutur Guru dan Siswa dalam Pembelajaran Bahasa dan Sastra Indonesia di Kelas XI SMA N 1 Blahbatuh. E Journal Program Pasca Sarjana Universitas Pendidikan Ganesha. 3.

Rohmadi, M. (2004). Pragmatik: Teori dan Analisis. Yogyakarta: Lingkar Media.
(2017).

Pragmatik: Teori dan Analisis. Surakarta: Yuma Pustaka.

Rahardi, Kunjana. (2000). Imperatif dalam Bahasa Indonesia. Yogyakarta: Duta Wacana University Press.

(2003). Berkenalan dengan Ilmu Bahasa Pragmatik. Malang: Dioma.

Sari, Riana Chandra. (2014). Tindak Tutur Direktif Guru pada Pembelajaran Bahasa Indonesia di Kelas X SMA Negeri 3 Boyolali. Skripsi. Pendidikan Bahasa Indonesia Universitas Sebelas Maret Surakarta.

Wiranty, W. (2015). Tindak Tutur dalam Wacana Novel Laskar Pelangi Karya Andrea Hirata (Sebuah Tinjauan Pragmatik). Jurnal Pendidikan Bahasa. Vol. 4. No. 2, Desember 2015.

Yuliana, R., Rohmadi, M. \& Suhita., R. (2013). Daya Pragmatik Tindak Tutur Guru dalam Pembelajaran Bahasa Indonesia pada Siswa Sekolah Menengah Pertama. Jurnal Penelitian Bahasa, Sastra Indonesia dan Pengajarannya. 2 (1): 3 .

Zaimar, O.K.S, \& Harahap, A.B. (2015). Teori Wacana. Jakarta: Penaku. 